\title{
Comparison of Ketamine and Pentazocine with Fentanyl and Propofol combination for anaesthesia during laparoscopic tubal ligation
}

\author{
Ovais Nazir $^{1 *}$, Asif Hussain Bhat ${ }^{1}$, Hamid Yatoo ${ }^{1}$, Sanjeevni Gupta ${ }^{1}$, Rajesh Misra ${ }^{2}$
}

\begin{abstract}
${ }^{1}$ Department of Anaesthesiology, Aruna Asif Ali Government Hospital, New Delhi, India
${ }^{2}$ Department of Anaesthesiology, Artemis Health Institute, Haryana, India
\end{abstract}

Received: 13 February 2019

Accepted: 07 March 2019

\author{
*Correspondence: \\ Dr. Ovais Nazir, \\ E-mail: ovais.khan83@gmail.com
}

Copyright: (c) the author(s), publisher and licensee Medip Academy. This is an open-access article distributed under the terms of the Creative Commons Attribution Non-Commercial License, which permits unrestricted non-commercial use, distribution, and reproduction in any medium, provided the original work is properly cited.

\begin{abstract}
Background: Laparoscopic tubal ligation have advantages of minimally invasive surgical technique, without risk of major haemorrhage, early postoperative ambulation and alimentation, making it suitable for ambulatory surgery. The choice of aneasthesia for laparoscopic ligation hence should consider the anaesthetic agents with a rapid onset of action and fast recovery time, with minimal problems for intraoperative control of haemodynamic, airway and pain relief as well as take consideration of the safety, quality, efficacy, and utilization of resources available to the given situation.

Methods: A total of 100 patients aged from 18 to 45 years who were scheduled to undergo laparoscopic tubal ligation were divided into Group I- Ketamine plus pentazocine group $(n=50)$, Group II- Propofol plus fentanyl group ( $=50)$ and studied for the intraoperative parameters (hemodynamic and respiratory profile), recovery time, postoperative side effects and discharge time.

Results: Intraoperatively MAP and HR were consistently higher in group I as compared to group II. Incidence of apnea and need for bag and mask ventilation was significantly more in Group II than in Group I as was the incidence of Bradycardia. Postoperative nausea and vomiting, psychomimetic effects were significantly more in Group I than in Group II. The time to reach modified PADSS $\geq 9$ (discharge time) was significantly longer in group I (140.3 \pm 12.82 min than in group II 102.2 $\pm 9.2 \mathrm{~min}), \mathrm{P}<0.01$.

Conclusions: Combination of ketamine and pentazocine gives good anaesthetic conditions during procedure with less incidence of airway and haemodynamic complications intraoperatively but more incidence of postoperative side effects like nausea, vomiting, psycomimetic effects, and time to meet discharge criteria, compared to propofol plus fentanyl.
\end{abstract}

Keywords: Day care anaesthesia, Ketamine, Laparoscopic tubal ligation, Pentazocine, Propofol

\section{INTRODUCTION}

Anaesthesia for day-care surgeries has evolved primarily as a result of safe perioperative care, multimodal pain control, and aggressive treatment of postoperative nausea vomiting and from a variety of socio-economic factors. ${ }^{1}$ Top priorities for successful outpatient surgery include the patient alertness, ambulation, analgesia and alimentation after surgery. Laparoscopic surgery benefits the patient by reducing postoperative morbidity, reduction in postoperative pain, better cosmetic result and faster return to normal activities. Hospital stay is shortened resulting in a reduction in overall medical cost. $^{2}$ Laparoscopic ligation does involve minimally invasive surgical technique, without risk of major haemorrhage, early postoperative ambulation and alimentation, hence making it suitable for ambulatory surgery. The choice of aneasthesia for laparoscopic 
ligation hence should consider the anaesthetic agents with a rapid onset of action and fast recovery time, and that do not cause problems with respect to intraoperative control of haemodynamics, airway and pain relief as well as take consideration of the safety, quality, efficacy, and utilization of resources available to the given situation.

Although both general anaesthesia with ETT or LMA are used successfully for sterilization procedures, however each has its advantages and disadvantages with regards to ambulatory surgery. 3,4

Similarly, neuraxial anaesthesia is being used for ligation either as a subachnoid block or reactivation of labour epidural in postpartum tubal ligation. ${ }^{5}$

However, the use of local anaesthesia along with intravenous sedation provides both advantages of local anaesthetic which includes analgesia during and after procedure with minimal side effects as well precluding the need for general anaesthesia. ${ }^{6}$

The present study was planned to compare two drug combinations pentazocine and ketamine combination with commonly used fentanyl and propofol combination for sedation during laparoscopic ligation and compare the intraoperative parameters (haemodynamic and respiratory profile), recovery time, postoperative side effects and discharge time between them.

\section{METHODS}

After approval by institutional ethics committee and obtaining a written informed consent from patients, this study was done in the time period from November 2017 to December 2018. A total of 100 patients aged from 18 to 45 years who were scheduled to undergo laparoscopic tubal ligation were studied.

\section{Exclusion criteria}

- Patients who had history of upper respiratory tract infections

- Receiving treatment for any psychiatric disease

- Allergy to the medications used for study

- Patients with seizure disorder

- Pregnancy induced hypertension

- Post-partum patients

- Gastro esophageal reflux

- Significant hepatic

- Cardiac

- Pulmonary diseases.

Included patients were allocated randomly (using computer generated random table method) into two equal groups:

Group I- Ketamine plus pentazocine group $(n=50)$,
Group II- Propofol plus fentanyl group ( $\mathrm{n}=50)$.

\section{Preanaesthetic preparation}

All patients were kept fasting for at least 6 hours before surgery. In the operating room, patients were monitored with ECG, non-invasive blood pressure and pulse oximetry. All the patients were given premedication with inj midazolam $1 \mathrm{mg}$ I.V given $5 \mathrm{~min}$ prior to the procedure and started with IV fluid after which the patient's incision site was infiltrated with $10 \mathrm{ml}$ of $0.25 \%$ bupivacaine infraumblically.

\section{Anaesthesia}

Group I received injection ketamine $1.5 \mathrm{mg} / \mathrm{kg}+$ pentazocine $0.6 \mathrm{mg} / \mathrm{kg}$ intravenously. Group II received injection propofol $1.5 \mathrm{mg} / \mathrm{kg}+$ fentanyl $1.5 \mu \mathrm{g} / \mathrm{kg}$. Supplemental dose of IV anaesthetic in the dose of $0.5 \mathrm{mg} / \mathrm{kg}$ ketamine in group I or $0.5 \mathrm{mg} / \mathrm{kg}$ propofol in group II was given if sedation level was inadequate during procedure and noted.

All the patients were given supplemental oxygen through Hudson mask with oxygen 5 litre/minute. Ventillation was assisted with bag and mask ventilation in case of apnea for more than 15 seconds or tongue fall or $\mathrm{SPO}_{2}<92 \%$.

Heart rate (HR), blood pressure (BP), peripheral oxygen saturation (SPO2), and respiratory rate (RR) were monitored and recorded at the following time intervals: Baseline, immediately before giving medication, $1 \mathrm{~min}$ after medication, and thereafter at 3-min intervals for half an hour or the end of procedure. ECG and SpO2 were monitored continuously.

Intraoperative side effects like respiratory depression (apnea longer than 15 seconds or $\mathrm{SpO} 2<92 \%$ ), tongue fall requiring jaw thrust or need for mask ventilation, hypotension (MAP less than $55 \mathrm{mmHg}$ ), and bradycardia (heart rate $<60$ beats per minute), visual disturbances, delirium, movements during surgery, phonation and any other side effect were recorded.

After the procedure (from end of skin stitching), all patients were shifted to recovery room and later on to the post-anesthesia care unit (PACU). In the PACU patients were assessed for vitals recording and nausea vomiting, sedation, emergence delirium, nystagmus and pain. The time to discharge was decided by the modified Post Anaesthetic Discharge Scoring System (PADSS). ${ }^{7}$

Modified Post Anaesthetic Discharge Scoring System (MPADSS) (Marshall and Chung):

\section{A) Vital signs}

2: Within $20 \%$ of preoperative value.

1: Within $20-40 \%$ of preoperative value. 
0: $40 \%$ of preoperative value.

\section{B) Ambulation}

2: Steady gait/ No dizziness.

1: With Assistance.

0: No ambulation/ dizziness.

\section{Nausea and vomiting}

\section{2: Minimal \\ 1: Moderate \\ 0 : Severe}

\section{Pain}

2: Minimal

1: Moderate

0 : Severe

Surgical bleeding

2: Minimal

1: Moderate

0: Severe

The total score is 10 .

PONV and pain (assessed by Visual Analog Scale) were recorded in PACU. Postoperative analgesic (injection diclofenac sodium $75 \mathrm{mg}$ iv in 100 normal saline) was administered when VAS score was $\geq 3$ and postoperative antiemetics (injection ondansetron $4 \mathrm{mg}$ ) for nausea and/or vomiting.

\section{Statistical analysis}

\section{Sample size and sample technique}

Based on pilot cases done and keeping the change in recovery time more than $15 \%$ as significant, 48 subjects were required in each group to be able to reject the null hypothesis that with probability (power) 0.9 . The Type I error probability associated with this test of this null hypothesis is 0.05 ( $\mathrm{p}$ value $<0.05$ ).

\section{Data analysis}

Statistical analysis was performed by the SPSS program for Windows, version 17.0. Continuous variables were presented as mean $\pm \mathrm{SD}$, and categorical variables as absolute numbers and percentages. Student t-test was used to compare between groups of normally distributed data. Categorical variables were analyzed using the chisquare test. For all statistical tests, a p-value less than 0.05 were taken to indicate a statistically significant difference.

\section{RESULTS}

As shown in Table 1, there was no significant differences between the groups in terms of baseline patient characteristics and the two groups did not differ preoperatively with respect to mean age, weight, Mean arterial pressure, Heart rate and respiratory rate (with $\mathrm{P}$ value $>0.05$ ).

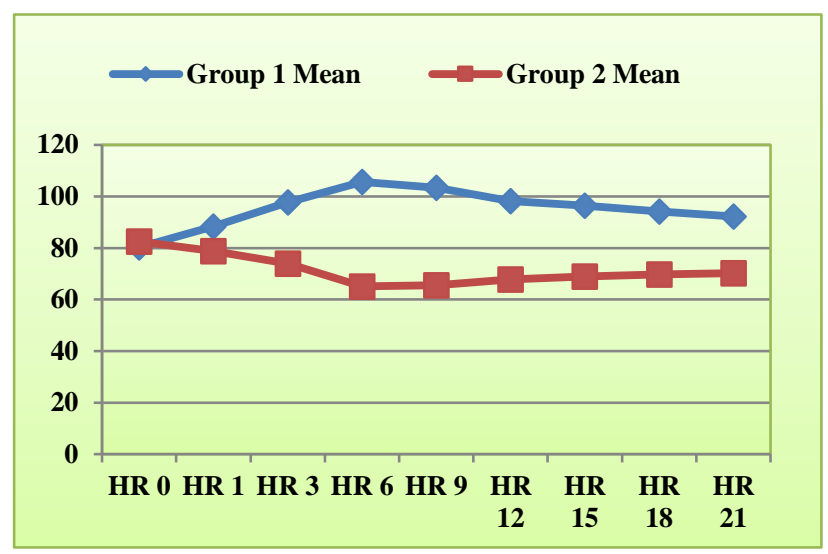

Figure 1: Mean heart rate (HR) during the procedure.

As shown in Figure 1, there was an intraoperative increase in mean heart rate (HR) from baseline in Group $\mathrm{I}$, and a decrease in mean heart rate (HR) from baseline in Group II.

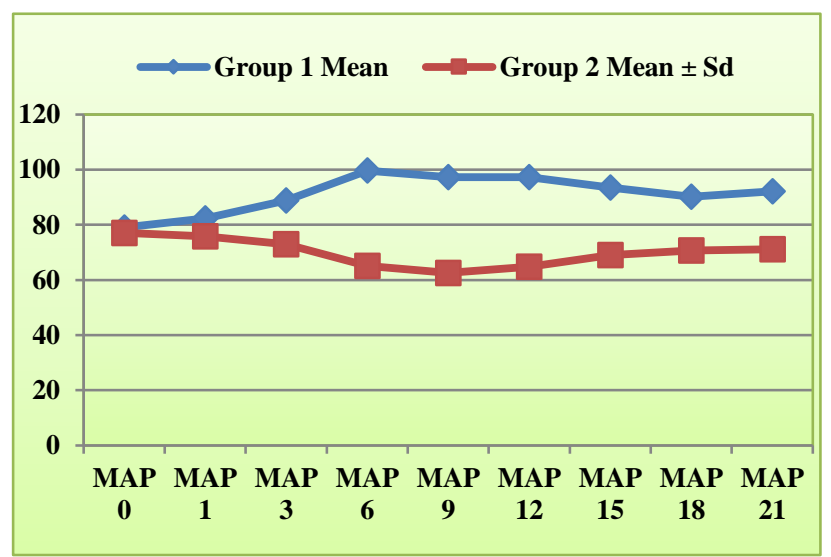

Figure 2: Mean arterial pressure (MAP) during procedure.

As shown in Figure 2, there was an increase in Mean arterial pressure (MAP) from baseline in Group I, and a decrease in Mean arterial pressure (MAP) from baseline Group II intraoperatively.

Table 1: Demographic data and haemodynamic parameters as mean \pm SD.

\begin{tabular}{|l|l|l|l|}
$\begin{array}{l}\text { Demographic } \\
\text { data and baseline } \\
\text { parameters }\end{array}$ & Group I & Group II & $\begin{array}{l}\text { P } \\
\text { value }\end{array}$ \\
\hline $\begin{array}{l}\text { Age (years) } \\
\text { Weight }(\mathrm{kg})\end{array}$ & $32.6 \pm 1.2$ & $31.8 \pm 1.4$ & 0.81 \\
\hline MAP (mmHg) & $53.35 \pm 4.3$ & $51.5 \pm 4.2$ & 0.52 \\
\hline HR & $77.1 \pm 6.9$ & $79.04 \pm 7.8$ & 0.49 \\
\hline RR & $82.5 \pm 7.2$ & $80.29 \pm 6.8$ & 0.51 \\
\hline
\end{tabular}


As shown in Table 2, the duration of procedure in Group I was $(13.2 \pm 3.2)$ minutes and in Group II $(13.6 \pm 3.1)$ minutes, difference that was statistically insignificant $\mathrm{p}$ value $>0.05$. Intraoperatively, 17 patients $(34 \%)$ in Group I and 15 patients (30\%) in Group II required supplemental doses of ketamine and propofol, respectively (difference statistically insignificant $\mathrm{p}$-value $>0.05)$.

Table 2: Intraoperative parameters in the two groups.

\begin{tabular}{|l|l|l|l|}
\hline & $\begin{array}{l}\text { Group 1 } \\
\text { N=50 }\end{array}$ & $\begin{array}{l}\text { Group 2 } \\
\text { N=50 }\end{array}$ & $\begin{array}{l}\text { P } \\
\text { value }\end{array}$ \\
\hline $\begin{array}{l}\text { Duration of } \\
\text { procedure (minutes) }\end{array}$ & $13.1 \pm 3.2$ & $13.6 \pm 3.1$ & 0.72 \\
\hline $\begin{array}{l}\text { Patients requiring } \\
\text { supplemental doses }\end{array}$ & 17 & 15 & 0.14 \\
\hline $\begin{array}{l}\text { Phonation during } \\
\text { procedure }\end{array}$ & 9 & 5 & 0.03 \\
\hline $\begin{array}{l}\text { Movements during } \\
\text { procedure }\end{array}$ & 10 & 5 & $<0.01^{*}$ \\
\hline $\begin{array}{l}\text { Patients requiring } \\
\text { mask ventilation or } \\
\text { assistance }\end{array}$ & 3 & 24 & $<0.01^{*}$ \\
$\begin{array}{l}\text { to maintain patent } \\
\text { airway and saturation }\end{array}$ & 2 & 19 & $<0.01^{*}$ \\
\hline Apnea & 2 & 7 & $<0.01^{*}$ \\
\hline Bradycardia & $\begin{array}{l}6.2 \pm 2.2 \\
\text { min }\end{array}$ & $\begin{array}{l}4.3 \pm 2.82 \\
\text { min }\end{array}$ & 0.037 \\
\hline \begin{tabular}{l} 
Recovery time \\
\hline
\end{tabular} & & \\
\hline
\end{tabular}

As shown in table 2 , incidence of other undesirable side effects like intraoperative undesirable movement, 10 patients $(20 \%)$ in group I and 5 patients $(10 \%)$ in group II and phonation in 9 patients $(18 \%)$ in group $I$ and in 5 patients $(10 \%)$ in group II, after surgical stimulation which was significantly higher in Group I than Group II.

Intraoperatively 2 patients (4\%) in Group I and 7 patients $(14 \%)$ in Group II had bradycardia (heart rate < $60 /$ minute) necessitating the use of atropine. The incidence of apnoea in Group I was 4\% (2 patients) and $38 \%$ (19 patients) in group II as was the need for bag and mask ventilation or airway assistance to maintain patent airway and saturation in Group I was 6\% (3 patients) and $48 \%$ (24 patients) in group II. The recovery time was $(6.2 \pm 2.2)$ minutes in Group I and $(4.3 \pm 2.82)$ minutes in Group II. As shown in Table 3, Sixteen patients (32\%) in group I and 10 patients $(20 \%)$ in group II had postoperative nausea and vomiting and had need for the administration of inj ondansetron $4 \mathrm{mg}$ intravenously. Five patients $(10 \%)$ in group I and nine patients (18\%) in group II complained of pain/discomfort in the postoperative period. Mean time to first dose of analgesic was $24.3 \pm 3.9$ minutes and $29 \pm 2.4$ minutes in group I and II respectively. The mean discharge time, decided by the modified Post Anaesthetic Discharge Scoring System (PADSS) $\geq 9$, in group Group I was longer $(140.3 \pm 12.82 \mathrm{~min})$ than in Group II (102.2 $\pm 9.2 \mathrm{~min})$. This difference in mean discharge time was statistically highly significant $(\mathrm{P}<0.01)$.

Table 3: Post-operative parameters.

\begin{tabular}{|l|l|l|l|}
\hline PONV & Group 1 & Group 2 & P value \\
\hline $\begin{array}{l}\text { Emergence } \\
\text { delirium }\end{array}$ & 16 & 10 & 0.03 \\
\hline $\begin{array}{l}\text { Post op } \\
\text { diclofenac } \\
\text { sodium } \\
\text { administration }\end{array}$ & 5 & 2 & $<0.01^{*}$ \\
\hline $\begin{array}{l}\text { Discharge time } \\
\text { min }\end{array}$ & $\begin{array}{l}140.3 \pm 12.82 \\
\text { min }\end{array}$ & $\begin{array}{l}102.2 \pm 9.2 \\
\text { min. }\end{array}$ & $<0.01^{*}$ \\
\hline
\end{tabular}

\section{DISCUSSION}

Ketamine produces dissociative anaesthesia characterized by profound analgesia, amnesia and cataleptic state. With appropriate dose operative conditions can be produced without causing respiratory or haemodynamic suppression. Pharyngeal and laryngeal reflexes remain active with patent airway during surgical anaesthesia. ${ }^{8}$ Propofol in short acting anaesthetic agent that produces good sedation and anaesthesia but simultaneously results in both respiratory and haemodynamic suppression. ${ }^{9}$ Propofol and fentanyl combination has been used previously in laparoscopic ligation procedures both for anesthesia as well as for procedural sedation with local anaesthesia and has shown good intraoperative results as well as faster postoperative recovery. ${ }^{10,11}$

Propofol in combination with ketamine has been used as procedural sedation during lap ligation and good intraoperative conditions have been obtained with some delay in recovery as compared to propofol fentanyl combination. ${ }^{11}$ The pentazocine has been used as a procedural sedation with promethazine or diazepam for sedation and analgesia during dental or gynecological procedures. ${ }^{12}$ However only two studies could be traced which involved ketamine plus pentazocine for sedation during procedures like abdominal tubectomy, D and C, D and $\mathrm{E}, \mathrm{I}$ and $\mathrm{D}$, removal of foreign bodies, excision of cysts and small tumors, eversion of sac, wound debridement and sequestrectomy and showed good results. $^{13,14}$

In this comparative study, it was observed that in propofol plus fentanyl group there was decrease in HR and MAP while in ketamine plus pentazocine group there was an increase in HR and MAP. There were 7 patients $(14 \%)$ in group II and 2 patients $(4 \%)$ in group I with incidence of bradycardia $\mathrm{HR}<60 \mathrm{bpm}$ requiring atropine. The decrease in MAP in propofol plus fentanyl group was due to decrease in afterload/ peripheral vascular resistance without compensatory increase in heart rate or cardiac output caused by propofol. ${ }^{9}$ The higher incidence of Bradycardia in group II can be explained as propofol 
causes bradycardia, effect which is augmented by use of fentanyl and vagally mediated reflex bradycardia due to stretching of peritoneum during $\mathrm{CO}_{2}$ insufflation. ${ }^{15,16}$

The incidence of apnea in group II (19 patients had apnea $>15 \mathrm{sec}$ ) was higher as compared to Group I as was the need for mask ventilation to maintain patent airway and arterial saturation (24 patients in Group II requiring mask ventilation due to fall in saturation). A similar results of apnea with propofol has been reported by young et al in 1997 using different doses of propofol for induction of anaesthesia (propofol $1 \mathrm{mg} / \mathrm{kg}$ (group 1) or $1.5 \mathrm{mg} / \mathrm{kg}$ (group 2) or $2 \mathrm{mg} / \mathrm{kg}$ (group 3) and found frequencies of apnea were $44 \%$ in group $1.63 \%$ in group 2 and $83 \%$ in group 3.17 As a respiratory depressant, propofol frequently produces apnea and the persistence of apnea depends on factors such as premedication, dose administered, and rate of administration, and may sometimes persist for longer than 60 seconds. ${ }^{18}$ Possibly as the result of depression of the central inspiratory drive, propofol may produce significant decreases in respiratory rate, minute volume, tidal volume, mean inspiratory flow rate, and functional residual capacity. ${ }^{19}$ The incidence of apnea and fall in saturation in group I was significantly less as ketamine has minimal effects on central respiratory drive and produces airway relaxation by acting on various receptors and inflammatory cascades and bronchial smooth muscle. ${ }^{20,21}$ Ketamine also leads to increase in HR and MAP due to sympathetic stimulation.

With regards to number of intraoperative supplemental doses, there was not much difference in two groups 17 in group I and 15 in group II. There was however difference in recovery time $6.2 \pm 2.2 \mathrm{~min}$ in group I and $4.3 \pm 2.82$ min in group II.

Postoperatively there was higher incidence of psychomimetic effects 11 patients $(22 \%)$ in group I and $2(4 \%)$ patients in group II, which may be due to its association with postoperative psychomimetic effects emergence delirium, unpleasant dreams, and hallucinations. Incidence ranges from 5\% to $30 \%$ which is mostly dose related. ${ }^{22}$ Use of midazolam with ketamine has been shown to decrease the psychomimetic side effects. $^{23}$ There was higher incidence of postoperative nausea and vomiting in group I 16 patients as compared to group II 10 patients that required ondensetron. There was a significant difference in time for return to modified PADSS score $\geq 9$ (discharge time) in group I $140.3 \pm 12.82$. minutes and in group II 102.2 \pm 9.2 minutes.

The combination of ketamine and pentazocine for sedation and anaesthesia in laparoscopic tubal ligation gives good anaesthetic conditions during procedure with less incidence of airway complications like apnea, tongue fall leading to decrease in $\mathrm{SPO}_{2}$ that needs airway assistance with bag and mask ventilation. Most of the procedures are carried out with supplemental oxygen through Hudson mask only. However, it is associated with more incidence of postoperative side like nausea vomiting, psychomimetic effects, and time to meet discharge criteria. Thus, propofol plus fentanyl combination is good for sedation and anaesthesia during laparoscopic ligation, however the ketamine and pentazocine combination can be of great use to anesthesiologist in remote areas and camps for laparoscopic ligation with maintained haemodynamics wherein most of the cases would not need airway assistance.

\section{CONCLUSION}

Combination of ketamine and pentazocine gives good anaesthetic conditions during procedure with less incidence of airway and haemodynamic complications intraoperatively but more incidence of postoperative side effects like nausea, vomiting, psychomimetic effects, and time to meet discharge criteria, compared to propofol plus fentanyl. Thus, propofol plus fentanyl combination is good for sedation and anaesthesia during laparoscopic ligation, however the ketamine and pentazocine combination can be of great use to anaesthesiologist in remote areas and camps for laparoscopic ligation with maintained haemodynamics wherein most of the cases would not need airway assistance.

\section{Funding: No funding sources}

Conflict of interest: None declared

Ethical approval: The study was approved by the Institutional Ethics Committee

\section{REFERENCES}

1. Urman RD, Desai SP. History of anesthesia for ambulatory surgery. Current Opinion in Anesthesiol. 2012;25(6):641-7.

2. Chui PT, Gin T, Oh TE. Anaesthesia for laparoscopic general surgery. Anaesthes Intens Care. 1993;21(2):163-71.

3. American Society of Anaesthesiologists Task Force on Obstetric Anaesthesia. Practice guidelines for obstetric anaesthesia: An updated report by the American Society of Anaesthesiologists Task Force on Obstetric Anaesthesia. Anaesthesiol. 2007;106(2):843-63.

4. Evans NR, Skowno JJ, Bennett PJ, James MF, Dyer RA. A prospective observational study of the use of the ProsealTM laryngeal mask airway for postpartum tubal ligation. Int J Obstet Anesthe. 2005;14(2):90-5.

5. Viscomi CM, Rathmel JP. Labor epidural catheter reactivation or spinal anesthesia for delayed postpartum tubal ligation: a cost comparison. J Clinic Anesthe. 1995;7(5):380-3.

6. Børdahl PE, Raeder JC, Nordentoft JØ, Kirste UN, Refsdal AR. Laparoscopic sterilization under local or general anesthesia? A randomized study. Obstet Gynecol. 1993;81(1):137-41.

7. Chung F, Chan VW, Ong D. A post-anesthetic discharge scoring system for home readiness after 
ambulatory surgery. J Clini Anesthe. 1995 Sep 1;7(6):500-6.

8. Corssen G, Miyasaka M, Domino EF. Changing concepts in pain control during surgery: dissociative anesthesia with CI-581. A progress reports. Anesth Analg. 1968;47(6):746-59.

9. Claeys M, Gepts E, Camu F. Haemodynamic changes during anaesthesia induced and maintained with propofol. BJA: British J Anaesthesia. 1988;60(1):3-9.

10. Vallejo MC, Romeo RC, Davis DJ, Ramanathan S. Propofol-ketamine versus propofol-fentanyl for outpatient laparoscopy: comparison of postoperative nausea, emesis, analgesia, and recovery. J Clinic Anesthe. 2002;14(6):426-31.

11. Singh R, Ghazanwy M, Vajifdar H. A randomized controlled trial to compare fentanyl-propofol and ketamine-propofol combination for procedural sedation and analgesia in laparoscopic tubal ligation. Saudi J Anaesthe. 2013;7(1):24.

12. Lalfamkima F, Debnath SC, Adhyapok AK. A Study of Promethazine Hydrochloride and Pentazocine Intramuscular Sedation Along with $2 \%$ Lidocaine Hydrochloride and Adrenaline and Comparison to Placebo Along with 2\% Lidocaine Hydrochloride and Adrenaline for Surgical Extraction of Mandibular Third Molar. J Maxillofacial Oral Surg. 2015;14(1):90-100.

13. R.P. Aggarwal, S. Sawhney.Combination of low dose ketamine and pentazocine-a clinical experience. Indian J Anaesth.2003;47(6):439-442.

14. Bala Subrahmaniyam K. Combination of Diazepam, Pentazocine, and Ketamine for minor surgical procedures. Indian J Anaesth. 1992;40(3):65-8.

15. Myles PS. Bradyarrhythmias and laparoscopy: a prospective study of heart rate changes with laparoscopy. Aus New Zealand J Obstet and Gynaecol. 1991;31(2):171-3.

16. Kazama T1, Ikeda K, Morita K. The pharmacodynamic interaction between propofol and fentanyl with respect to the suppression of somatic or hemodynamic responses to skin incision, peritoneum incision, and abdominal wall retraction. Anesthesiol. 1998;89(4):894-906.

17. Yong Seok Park, Ik Hyun Choi, Ji Hee Kim. Duration and Frequency of Apnea and Frequency of Unconsciousness with Propofol according to Single Injection Dosage. Korean J Anesthesiol.1997;32(5):829-34.

18. Langlay MS, Heel RC. Propofol: A review of its pharmacodynamic and pharmacokinetic properties and use as an intravenous anesthetic. Drugs. 1988;35:334-72.

19. Sebel PS, Lowden JD. Propofol: a new intravenous anesthetic. Anesthesiol.1989;71(2):260-77.

20. Reves JG, Glass PS, Lubarsky DA, McEvoy MD, Ruiz RM. Intravenous anaesthetics. In: Miller RD, editor. Miller's Anaesthesia. 7th ed. USA: Churchill Livingstone; 2010. pp. 719-71.

21. Goel S, Agrawal A. Ketamine in status asthmaticus: A review. Indian J Crit Care. 2013;17(3):154-61.

22. White PF, Ham J, Way WL, Trevor A. Pharmacology of ketamine isomers in surgical patients. Anesthesiology: J Am Soc Anesthesiol. 1980;52(3):231-9.

23. Somashekara SC, Govindadas D, Devashankaraiah G, Mahato R, Deepalaxmi S, Srinivas V, Murugesh JV. Midazolam premedication in attenuating ketamine psychic sequelae. J Basic Clinic Pharma. 2010;1(4):209.

Cite this article as: Nazir $\mathrm{O}$, Bhat $\mathrm{AH}$, Yatoo $\mathrm{H}$, Gupta S, Misra R. Comparison of Ketamine and Pentazocine with Fentanyl and Propofol combination for anaesthesia during laparoscopic tubal ligation. Int J Reprod Contracept Obstet Gynecol 2019;8:152530. 